\title{
Ensino, aprendizagem e novas tecnologias: relações entre abordagens teóricas clássicas e contemporâneas
}

Teaching, learning and new technologies: the relations among theoretical classical and contemporary approaches

\author{
Rosana Maria Luvezute Kripka ${ }^{1}$ \\ Lori Viali \\ Adriana Dickel ${ }^{3}$ \\ Regis Alexandre Lahm ${ }^{4}$
}

\section{Resumo}

O artigo visa apresentar um paralelo entre as teorias clássicas e contemporâneas de ensino e aprendizagem com as teorias modernas de ensino e de aprendizagem com o uso das Tecnologias Digitais da Informação e Comunicação (TDIC). Foi realizado um estudo investigativo teórico, segundo a abordagem da pesquisa qualitativa, com vistas a identificar teorias existentes sobre ensino e aprendizagem com O uso das TDIC e suas relações com abordagens teóricas clássicas e contemporâneas. Conclui-se fazendo um paralelo entre as teorias construtivista, cognitivista, humanista e sócio-histórica com o construcionismo e o conectivismo, destacando proximidades e distanciamentos entre o grupo clássico e contemporâneo com a teoria moderna.

Palavras chave: Teorias de Ensino e de Aprendizagem Clássicas; Teorias de Ensino e de Aprendizagem Contemporâneas; Teorias de Ensino e de Aprendizagem com Novas Tecnologias.

\section{Abstract}

The article aims to present a parallel between the classical and contemporary theories of teaching and learning with similar modern theories which make use of Information and Communication Digital Technologies (ICDT). A theoretical investigative study was carried out utilizing the qualitative research approach, with focus on identifying existing theories about teaching and learning with the usage of ICTs and their relations with the classical and contemporary theoretical approaches. It concludes by making a parallel between constructivist, cognitivist, humanist and socio-historical theories with constructionism and connectivism, highlighting the differences and similarities of classic and contemporary theories when put in contrast regarding modern ones.

Keywords: Classical Teaching and Learning Theories; Contemporary Teaching and Learning Theories; Teaching and Learning Theories with New Technologies.

\footnotetext{
${ }^{1}$ Universidade de Passo Fundo | rkripka@upf.br

${ }^{2}$ Pontifícia Universidade Católica do Rio Grande do Sul | viali@pucrs.br

${ }^{3}$ Universidade de Passo Fundo | dickel@upf.br

${ }^{4}$ Pontifícia Universidade Católica do Rio Grande do Sul | lahm@pucrs.br
} 


\section{Introdução}

Muito se fala a respeito do uso das Tecnologias Digitais da Informação e Comunicação (TDIC) em sala de aula e muitas experiências são divulgadas no meio científico, tendo em vista sua socialização, a exemplo dos trabalhos apresentados por Souza Filho; Souza e Gibin (2017); Silva, Porto e Medeiros (2017); Urdaneta, Gonzalez e Castillo (2017) ou Faria, Romanello e Domingues (2018). No entanto, nem sempre as atividades apresentadas remetem aos fundamentos teóricos utilizados em suas elaborações, ficando implícitos no processo.

Conforme Souza (2006), para explorar as potencialidades do uso das TDIC no ensino, é necessário esclarecer quais são as teorias que orientam as práticas pedagógicas educacionais. As teorias educacionais vigentes foram formuladas antes do surgimento das tecnologias digitais, em particular, a WWW. Assim, o objetivo deste artigo é fazer um contraponto entre as teorias educacionais existentes (clássicas) e a teoria do construcionismo (contemporânea) de Papert (1994) e especialmente o conectivismo (moderna) de Downes (2005, 2007, 2009) e Siemens (2004, 2006, 2008).

Ramos (2008) indica a necessidade de o professor ser um "epistemólogo" de si mesmo, ou seja, compreende ser necessário que esse profissional pense criticamente sobre (seu) conhecimento, para que possa compreender como ele se constituiu e como continua sendo construído ao longo da vida, analisando seu processo histórico e sua validade em sua própria prática. Para isso, indica que o professor deve assumir em sua vida profissional uma postura reflexiva epistemológica. Sugere que, quando analisa sua concepção sobre aprendizagem, o professor também faz uma reflexão epistemológica sobre alguma teoria do conhecimento e que somente poderá modificá-la significativamente, tendo em vista seu aprimoramento, após se dar conta de suas convicções e crenças relacionadas à sua prática.

Com esse propósito, são apresentadas as principais teorias clássicas, contemporâneas e modernas sobre o ensino e a aprendizagem, encontradas na literatura, e algumas reflexões sobre proximidades ou distanciamento entre essas teorias de aprendizagem e a teoria moderna do conectivismo, que foi elaborada especialmente para a aprendizagem com as TDIC.

\section{Concepções sobre o ensino e a aprendizagem com as TDIC}

Segundo, Oliveira, Costa e Moreira (2001), didaticamente, distinguem-se três tipos de concepções que orientam a prática com a tecnologia educacional: a empirista, a racionalista e a construtivista.

Na concepção racionalista, o pensamento - ou a razão - é a principal fonte do conhecimento humano, e ele independe da experiência (HESSEN, 2000). Para Oliveira, Costa e Moreira (2001), nessa concepção, as atividades de conhecimento estão centradas no aluno, uma vez que se acredita que o potencial cognitivo e o amadurecimento orgânico de suas estruturas são os elementos que propiciam a aprendizagem, não necessitando de mediação. Nesse caso, indicam que as ferramentas tecnológicas são utilizadas apenas para mensuração dos estágios de desenvolvimento cognitivo, citando como exemplo os testes de Ql ou jogos usados para identificação dos estágios de desenvolvimento. Ou seja, são tratadas como acessórios no processo de ensino e de aprendizagem.

A concepção empirista, segundo Hessen (2000), contrapõe-se ao racionalismo, já que a única fonte do conhecimento humano é a experiência e também que a consciência 
cognoscente não se constitui pela razão, mas pela experiência. Segundo Oliveira, Costa e Moreira (2001), essa concepção baseia-se em estímulos e aferição de respostas, e o professor é considerado o "detentor do conhecimento", responsável por estimular a aprendizagem de seus alunos, os quais são entendidos como tábulas rasas, que, de modo passivo, recebem os conteúdos depositados pelo professor, de modo que ao conhecimento é conferido o caráter atomístico e não relacional.

Para os autores, nessa abordagem, o uso de recursos tecnológicos visa transferir para ambientes tecnológicos a instrução programada por meio de recursos multimídias, o que possibilita que o acesso à informação seja mais agradável, e também permite aos alunos adequar seus ritmos individuais ao processo de apreensão do conhecimento. Indicam que, pelo fato de tais estratégias contribuírem pouco com o desenvolvimento humano e por não exigirem grandes mudanças paradigmáticas, talvez essas sejam as mais pobres concepções em relação ao uso de tecnologias. No entanto, os autores ressaltam que a busca autônoma pelo conhecimento pode ser potencializada por meio de recursos tecnológicos devido à facilidade de acesso aos materiais bibliográficos disponíveis para consulta.

A concepção construtivista, segundo Oliveira, Costa e Moreira (2001), surge como uma proposta para tentar superar o distanciamento entre as concepções empiristas e racionalistas. Foi fortemente influenciada pelas teorias interacionistas, especialmente pela teoria cognitivista de Jean William Fritz Piaget (1896 - 1980) e pela teoria sócio-histórica de Lev Semyonovich Vygotsky (1896 - 1934). Nessa perspectiva, o conhecimento e os modos de pensar são construídos por meio da exploração e manipulação de objetos e ideias, e a aprendizagem é entendida como decorrente da interação do indivíduo com o meio. Desse modo, é a concepção que melhor propicia a exploração dos recursos tecnológicos como estratégia que objetiva a melhoria dos processos de ensino e aprendizagem.

Jonassen (1996) indica que o construtivismo é uma filosofia de aprendizagem. Para o autor, nessa filosofia, o conhecimento é entendido como uma construção humana, pois fornece elementos para a busca de sentidos e significados para fenômenos do mundo em que se vive. Afirma que, como existem diferentes percepções e múltiplas perspectivas, o conhecimento de cada pessoa não retrata o meio físico, mas sim, o entendimento que se tem sobre o fenômeno observado, resultante das interações com o meio. Ressalta que, como a aprendizagem se dá por meio do diálogo e por interações sociais, o conhecimento pessoal construído não é necessariamente individual, pois pode remeter ao significado construído por um grupo social.

Lopes (2014), em sua tese de doutorado investigando futuros professores de matemática, verificou que as concepções dos participantes, em relação à abordagem pedagógica das TDIC, podem ser divididas em concepções instrucionistas e construcionistas. Constataram ainda que essas concepções eram compartilhadas, da mesma forma, pelos professores coordenadores dos cursos em que foi realizada a investigação. Esse resultado corrobora, em parte, o que foi encontrado por Oliveira, Costa e Moreira (2001), mencionado nos parágrafos anteriores.

\section{Teorias de aprendizagem clássicas}

As teorias clássicas de aprendizagem, conforme destacado por Alves (2014), podem ser classificadas, de acordo com suas abordagens, em quatro grupos: as teorias comportamentais (ou behavioristas), as cognitivas, as humanistas e as sócio-históricas. 
A autora afirma que, na abordagem comportamentalista (ou behaviorista), se destaca a experiência como base do conhecimento. A aprendizagem ocorre quando há uma mudança no comportamento do sujeito, por meio de estímulos e respostas, destacando-se a influência de estímulos externos, positivos ou negativos, do ambiente e da experiência vivenciada sobre o comportamento do sujeito. O principal representante dessa abordagem, segundo a autora, seria Burrhus Frederic Skinner (1904 - 1990), pioneiro no estudo da Psicologia Experimental e autor da Teoria do Condicionamento Operante.

Outro representante dessa abordagem seria Albert Bandura (1925 - ), criador da Teoria da Aprendizagem Social, a qual visa a uma aproximação entre a abordagem behaviorista e a cognitivista. Para ele, a aprendizagem decorre da imitação do comportamento dos outros ou da modelagem social e se dá a partir de algumas etapas: atenção, retenção, reprodução e motivação.

Robert Mills Gagné (1916 - 2002), autor do Modelo de Processamento de Informação, que adotou uma abordagem em relação à aprendizagem mais cognitivista do que comportamentalista, também poderia ser incluído nessa abordagem, uma vez que os eventos de aprendizagem ocorrem por meio de eventos externos de estímulo e resposta e de eventos internos, os quais ocorrem no sistema nervoso central do estudante, inferidos por meio de observações externas. Para ele, a aprendizagem se dá por meio de oito fases: motivação, apreensão, aquisição, retenção, lembrança ou rememoração, generalização, desempenho e retroalimentação.

Segundo Machado e Farias (2012), na abordagem behaviorista, o foco da aprendizagem está na mudança do comportamento por meio dos estímulos e das respostas observáveis, e o professor é responsável pelo ensino e pelas metas que se deseja alcançar. O aluno, passivo, recebe o conhecimento que é transmitido, aprendendo individualmente por meio da sua experiência. O ensino, portanto, acontece por meio de aulas expositivas, por meio das quais se concebe que ocorra a aquisição do conhecimento científico, o que possibilita indicar a concepção empirista do professor. As autoras destacam que essa teoria foi utilizada como base das primeiras gerações de Ensino Assistido por Computador (EAC).

Em relação às teorias cognitivistas, Alves (2014) indica que o foco está na compreensão do desenvolvimento das estruturas cognitivas do sujeito e nos aspectos relacionados à aprendizagem, a qual decorre da interação do sujeito com o meio. As teorias cognitivistas visam explicar como o ser humano conhece o mundo e como é possível construir conhecimentos por meio de interações. Assim, elas exploram como se dá o desenvolvimento humano, visando à construção de conhecimentos por meio de ambientes de aprendizagem. Esses ambientes propiciam 0 desenvolvimento de mecanismos intelectuais, permitindo a formação de novos conceitos, por meio do estabelecimento de relações, de levantamento de hipóteses e de possíveis soluções. O desenvolvimento humano se dá por meio de uma evolução, por processos de maturação ao longo da vida. Os principais representantes dessa abordagem, segundo Alves (2014), seriam Jean William Fritz Piaget (1896 - 1980), David Paul Ausubel (1918 - 2008) e Jerome Seymour Bruner (1915 2016).

Segundo a autora, a teoria Piagetiana visa ao estudo dos mecanismos responsáveis pelo desenvolvimento do conhecimento humano, o qual se dá por meio de estágios do desenvolvimento cognitivo. Para Piaget, o conhecimento é gerado pela interação do sujeito com o meio envolvendo estruturas internas chamadas de esquemas ou de estruturas cognitivas. O conhecimento ocorre em um processo contínuo de construção de estruturas 
cada vez mais complexas, resultantes da ação do sujeito sobre o meio. Esse processo de aprendizagem inclui a assimilação, a acomodação e a adaptação.

Sobre a teoria da aprendizagem significativa, de Ausubel, também chamada de teoria de assimilação, Alves (2014) indica que, diferentemente dos propósitos de Piaget, o seu foco consistiu em compreender e explicar como se dava o processo de ensino e de aprendizagem ocorridos em sala de aula. Para Ausubel, a aprendizagem significativa ocorre somente quando o aluno está disposto a aprender e quando existem conhecimentos prévios, já existentes na estrutura cognitiva dos estudantes, chamados por ele de "conceitos subsunçores". Para ele, tais conceitos, ao se relacionarem às novas informações, possibilitam a assimilação de novos conhecimentos de modo significativo. Desse modo, orienta que o conteúdo escolar deve ser trabalhado por meio de materiais que sejam potencialmente significativos, de modo a acionar os conhecimentos prévios relevantes dos estudantes, possibilitando a aprendizagem significativa de conceitos mais amplos ou complexos, de modo não arbitrário.

Quando a aprendizagem não tem relação com conceitos já existentes, Ausubel considera que houve uma aprendizagem mecânica. Assim, o professor deve apresentar as informações de modo organizado, propondo desequilíbrios e desafios que possibilitem perceber como os novos conceitos se relacionam aos conceitos já existentes em suas estruturas cognitivas. Para tanto, sugere que, no planejamento do ensino, sejam considerados os princípios da Diferenciação Progressiva; Reconciliação Integrativa; Organização Sequencial e Consolidação. Moreira e Masini (1982) indicam que, nessa teoria, o armazenamento de informações é um processo complexo, organizado pela estrutura mental do cérebro humano. A estrutura cognitiva consiste numa estrutura hierárquica de conceitos, constituída de abstrações advindas da experiência do indivíduo. O processo de ancoragem da nova informação implica crescimento e modificação dos conceitos subsunçores já existentes. Assim, para Ausubel, a teoria da aprendizagem significativa pressupõe a construção e o aperfeiçoamento de uma rede semântica própria para cada indivíduo.

Em relação à teoria de Bruner, Alves (2014) afirma que, inicialmente, por ter sido influenciado pela teoria de Piaget, considerou que o desenvolvimento psicológico era resultante de um processo evolutivo de representação de mundo. No entanto, ao longo de sua vida, ao conhecer as ideias de Vygotsky, suas reflexões o levaram a abandonar a teoria cognitivista e a considerar a cultura como um elemento importante na constituição do desenvolvimento do sujeito. Assim, passou a investigar como o desenvolvimento da mente estaria relacionado à construção de significados produzidos nas interações dos sujeitos com o meio social. Para Bruner, cada sujeito atribui um significado próprio a uma informação, mas, se compartilhado socialmente, pode condicionar modos de pensar e de agir dos sujeitos que vivem em sociedade. Assim, defende que o desenvolvimento da mente humana está relacionado à construção de significados por seres humanos na relação com o meio em que vivem, sendo esse um processo criativo, pessoal e subjetivo. A autora afirma que, segundo Bruner, a escola deveria considerar esse aspecto cooperativo na construção do conhecimento.

Conforme Machado e Farias (2012), na abordagem pedagógica, segundo as teorias cognitivistas, o professor deve assumir o papel de orientador, visando à manipulação dos processos mentais dos alunos, os quais atuam ativamente como observadores das suas interações e como solucionadores de problemas. No entanto, o conhecimento continua 
sendo absoluto e transmissível; ao passo que a aprendizagem centrada no aluno consiste na representação simbólica da realidade exterior, realizada pela mente humana.

De acordo com Alves (2014), as teorias de aprendizagem com abordagem humanista surgiram na década de 1960 visando considerar aspectos integrais da pessoa nas perspectivas afetiva, social, psicomotora e da personalidade humana, como processos que estão em contínuo desenvolvimento, e contemplar diferentes aspectos que não eram considerados nem pelo comportamentalismo nem pelo cognitivismo. Nessa abordagem, são privilegiadas as relações interpessoais e suas relações com o desenvolvimento do sujeito, que atua como uma pessoa integrada na construção e na organização da realidade em que vive.

Alves (2014) aponta que o principal representante da abordagem humanista é Carl Ranson Rogers (1902 - 1987), que, em sua teoria, propõe um modelo de ensino nãodiretivo, centrado no aluno, que privilegia o desenvolvimento do domínio emocional mais do que o domínio cognitivo. Nessa abordagem, o professor deve orientar o crescimento pessoal, assumindo o papel de facilitador das relações interpessoais, já que o importante não é ensinar, mas propiciar a aprendizagem dos alunos, ajudando-os no seu crescimento e valorizando a criatividade. O objetivo é ajudar o aluno a conhecer suas necessidades e, tendo em vista a realização plena do seu potencial humano, ajudá-lo a autodirigir sua educação. Os métodos de ensino são centrados nos alunos, individualizados e flexíveis, e valorizam a autorrealização.

O último grupo de teorias de aprendizagem é caracterizado pela abordagem sóciohistórica, a qual, para Alves (2014), se propôs a construir uma Psicologia Dialética, que visava compreender a aprendizagem como fenômeno situado na relação dialética entre o sujeito e o meio social. A autora destaca que, entre vários teóricos que a representam, o principal deles é Lev Semanovich Vygotsky (1896 - 1934), a quem coube investigar a origem social do pensamento. Para ele, a aprendizagem ocorre a partir de interações com o meio social, em meio às quais a linguagem tem um papel fundamental. Destaca que o desenvolvimento das estruturas mentais próprias do ser humano - ou seja, das funções psicológicas superiores se dá ao longo da história social, sendo essas estruturas mediadas socialmente por instrumentos e símbolos construídos culturalmente. Assim, para Vygotsky, o conhecimento é construído e internalizado por meio de interações sociais. Alves (2014) destaca na teoria do referido autor o conceito de zona de desenvolvimento proximal (ZDP), entendida como o plano intermediário entre o conhecimento real e o plano superior de desenvolvimento potencial, que o sujeito ainda pode alcançar em seu estágio de conhecimento. Segundo Vygotsky, a ZDP caracteriza-se por ser o plano onde o professor deve trabalhar com os conteúdos, visando estimular a aprendizagem dos alunos e, portanto, o processo de construção do conhecimento e o desenvolvimento. Para tanto, cabe ao professor o planejamento e a reorganização contínuos de experiências significativas e colaborativas, tendo em vista a apropriação de conhecimentos. Machado e Farias (2012) indicam que, nessa abordagem, o aluno tem um papel ativo no processo de aprendizagem e apontam que o ensino deve ser fomentado e orientado pelo professor.

\section{Teorias de ensino e de aprendizagem com o uso das TIC}

As teorias de aprendizagem comportamentalistas, cognitivistas e construtivistas são, conforme aponta Siemens (2004), as mais utilizadas em ambientes escolarizados, e elas 
foram desenvolvidas em épocas em que as tecnologias digitais ainda não existiam como recursos pedagógicos. Assim, é possível perceber claramente que suas potencialidades para o ensino e aprendizagem não foram consideradas nas teorias apresentadas.

No entanto, nos últimos trinta anos, muitos pesquisadores, inspirados nas teorias clássicas ou pela proposição de novas teorias, têm se dedicado à investigação dos usos desses recursos, considerando as diferentes possibilidades de inserção das TIC, de modo a favorecer os processos de ensino e aprendizagem, especialmente em ambientes escolarizados.

Considerando os contextos emergentes da era digital e os pressupostos dessa linha investigativa, Seymour Papert (1994) apresentou, em 1980, o conceito de construcionismo, e George Siemens (2004, 2006, 2008) e Stephen Downes (2004, 2006, 2008) apresentaram o conectivismo como novas teorias da aprendizagem envolvendo o uso de recursos tecnológicos.

\section{O construcionismo de Seymour Papert}

Ao propor o construcionismo em 1980, Papert (1994) reconheceu a existência, na época, de duas tendências de sinergia potencial no mundo: a tecnológica e a epistemológica. Indicou que a mesma revolução tecnológica que gerou a necessidade de busca por novas estratégias de aprendizagem seria aquela que forneceria os meios para que isso se efetivasse, possibilitando diversos modos para a melhoria na qualidade do ensino. Afirmou, ainda, que a tendência epistemológica que se refere à revolução no pensamento acerca do conhecimento também pode ser potencializada pelo uso das tecnologias, valorizando as diferentes formas de aprender, de se expressar, de obter informações e de se comunicar, explorando o amor das crianças pelas máquinas. Buscando responder a como o relacionamento entre crianças e computadores afetava a aprendizagem, Papert propôs o construcionismo, em oposição ao instrucionismo, o qual propugnava o máximo de aprendizagem com o mínimo de ensino.

Segundo o autor, o construcionismo consiste numa reconstrução pessoal do construtivismo proposto por Piaget, indicando que também considera um "conjunto de construção" e que valoriza o papel das construções no mundo como apoio para o desenvolvimento de construções mentais. Assim, indica que o desenvolvimento intelectual inclui a necessidade de construção de um artefato externo, que deve ser estimulado por uma situação ou um problema que desperte o interesse pela aprendizagem.

Nesse contexto, Papert (1994), como educador matemático, destaca a importância do uso dos computadores como ferramentas indispensáveis para a aprendizagem, por possibilitarem aos alunos externarem suas construções mentais, exibirem, discutirem e analisarem os artefatos construídos, tais como a construção de programas de computador, ou gráficos, ou de imagens quaisquer. Também indica que o uso de computadores: estimula a criatividade e a criação de ambientes ativos de aprendizagem possibilitando testar ideias e hipóteses; permite o desenvolvimento de trabalhos colaborativos e a aprendizagem por meio de reflexões; estimula o desenvolvimento do senso crítico e ressalta a vantagem de possibilitar a abordagem de problemas por meio de diferentes estratégias, que podem ser compartilhadas em sala de aula, permitindo a finalização dos trabalhos em diferentes níveis e respeitando os gostos e habilidades técnicas dos alunos. Assim, na proposta construcionista, com o auxílio do computador, ao visualizar suas construções 
mentais, o aluno relaciona o concreto e o abstrato de modo interativo, favorecendo a construção do próprio conhecimento.

\section{A Teoria do Conectivismo de George Siemens e Stephen Downes}

Siemens (2004) afirma que, devido ao crescimento cada vez mais rápido do conhecimento, existem algumas tendências significativas sobre aprendizagem que devem ser consideradas, entre elas o fato de que a atuação profissional exige conhecimento diversificado e não somente conhecimentos específicos. A aprendizagem deve ser contínua, de modo a possibilitar o acompanhamento da rápida evolução do conhecimento. Além disso, indica que se aprende muito mais informalmente em redes sociais ou profissionais do que em ambientes formais de ensino, e que nosso cérebro está sendo modificado pelas novas formas de pensamento propiciadas pelas tecnologias digitais. Afirma ainda que a aprendizagem não se restringe ao indivíduo, mas se estende às organizações às quais está vinculado, e compreende que o processamento da informação, que anteriormente era realizado apenas por processos cognitivos, atualmente pode ser realizado por meio do uso de tecnologias. Salienta que mais importante do que saber fazer é necessário saber reconhecer, de modo crítico, onde se localiza o conhecimento necessário para resolver um problema novo que se apresenta.

Siemens (2004) defende que as teorias behavioristas, cognitivistas e construtivistas, que se orientam pela compreensão de como o sujeito aprende, ou seja, como se dá o processo de aprendizagem que ocorre dentro do indivíduo, não respondem às questões que se apresentam nas tendências contemporâneas, especialmente em relação a como a aprendizagem ocorre fora das pessoas, em organizações. Indica que, nos dias atuais, é necessário saber agir profissionalmente sem necessariamente possuir a aprendizagem primária pessoal sobre o assunto, mas é preciso ser capaz de reconhecer conexões e padrões e sintetizá-los para usos adequados. Defende que a aprendizagem ocorre por processos contínuos, não lineares, que exigem operações cognitivas capazes de tratar com armazenamento e recuperação de informações, de modo a possibilitar atualização e emprego do conhecimento disponível em rede, sem a necessidade do completo entendimento pessoal daquele conhecimento.

Nesse sentido, propôs a teoria do conectivismo como uma abordagem inovadora, que se contrapõe às tradicionais e que considera que a aprendizagem não se dá apenas pela experiência pessoal, pois defende que não é possível experimentar tudo para (re)construir o conhecimento existente, disponível no caos da rede, ou o conhecimento científico organizado pela sociedade contemporânea. Considera que a tarefa fundamental da aprendizagem está na capacidade de reconhecimento e de adaptação às mudanças de padrão que se apresentam, que exigem aprendizagem por auto-organização. Entende que esse micro processo ocorre em construções de conhecimentos maiores, em ambientes de redes institucionais ou corporativos. Indica que os princípios que orientam o conectivismo correspondem à integração da teoria do caos, da rede, da complexidade e da autoorganização. Afirma que a aprendizagem não é controlada pelo sujeito, ocorrendo em ambientes nebulosos de mudança de elementos centrais. Assim, entende que aprender, definido como conhecimento acionável, pode ocorrer fora do indivíduo, dentro de uma rede organizada (banco de dados), por meio da proposição de conexões inovadoras entre diferentes conhecimentos, com as quais o sujeito e a organização aprendem. Considera 
essas possibilidades de inovações ou de estabelecimento de novas conexões mais importantes do que o estado atual da rede de conhecimento já constituída.

Segundo o autor, são princípios do conectivismo: o conhecimento e a aprendizagem ocorrem na diversidade de opiniões; a aprendizagem pode estar fora do indivíduo, em dispositivos tecnológicos, consistindo no processo de construção de conexões entre conhecimentos já estabelecidos; para facilitar a aprendizagem contínua, é necessário o desenvolvimento do saber crítico, considerado uma habilidade fundamental para perceber conexões entre áreas, tanto para manter, quanto para estabelecer novas conexões entre conhecimentos já existentes; a intenção da atividade de aprendizagem é a atualização da rede de conhecimento; e a tomada de decisão também é considerada como um processo de aprendizagem.

Siemens (2004) defende que o ponto de partida do conectivismo é o indivíduo, pois é a rede de seu conhecimento pessoal que impulsiona o aprimoramento dos conhecimentos organizacionais, os quais retroalimentam e proporcionam ao indivíduo novos aprendizados. São os focos das conexões das redes que possibilitam a atualização e o ciclo de desenvolvimento dos indivíduos e das organizações. Indica que é essa ampliação da aprendizagem e do conhecimento, por meio de uma rede pessoal, que resume o conectivismo. Salienta que o conectivismo é um modelo que considera que, na sociedade atual, aprendizagem já não é mais considerada como uma atividade interna individualizada apenas e defende que mais importante do que o conhecimento atual é a capacidade de aprender para construir o conhecimento futuro.

Mota (2009) aponta que Stephen Downes (2005, 2007, 2009) também realizou pesquisas nessa linha e apresentou contribuições para as teorias do conectivismo e do conhecimento conectivo. Além disso, Mota (2009) indica que não existe consenso na comunidade científica em considerar a teoria do conectivismo como uma nova teoria geral de aprendizagem, apresentando as críticas de Kop e Hill (2008), Verhagen (2006) e Kerr (2007). No entanto, informa que tanto Siemens (2006, 2008) quanto Downes (2007; 2009), após essas críticas, buscaram esclarecer seus conceitos, explicando melhor seus argumentos.

Assim, o conectivismo foi proposto por Siemens (2004) como uma nova teoria de aprendizagem, alternativa às três teorias mais utilizadas em ambientes de ensino - o behaviorismo, o cognitivismo e o construtivismo -, já que consideraria os impactos do uso das tecnologias digitais, especialmente em ambientes sociais subjacentes ao processo de aprendizagem que ocorrem continuamente ao longo da vida, em redes pessoais ou sociais, em tarefas associadas a uma profissão ou em comunidades de práticas. Para ele, um aspecto fundamental da nova era digital é que a tecnologia possibilita, pelo processamento cognitivo da informação, externalizar, apoiar ou transferir muitos processos mentais.

Salienta que é necessário propor métodos diferenciados que possibilitem explorar os vários aspectos da aprendizagem, afirmando que são as comunidades de aprendentes que podem melhor acomodar e suprir essas diversas necessidades, em ambientes que permitam ir além da sala de aula, entendendo a noção de aprendizagem como uma rede, uma comunidade ou uma ecologia. Indica que também as estruturas e os espaços de aprendizagem estão em transformação, e, inspirado em Ivan Illich (1926 - 2002) e em Paulo Freire (1921 - 1997), sugere que a sala de aula esteja aberta para novas possibilidades e que - professor adote uma pedagogia participativa, possibilitando seu desdobramento em novas ecologias de aprendizagens (ou espaços), que valorize a diversidade, a reflexão e a participação ativa do aprendente por meio do diálogo, na constituição de comunidades e redes (Siemens, 2008). 


\section{Reflexões e perspectivas sobre uso das TIC no ensino e na aprendizagem}

Ao serem consideradas as teorias clássicas de aprendizagem, é possível perceber que a maioria delas foi elaborada quando ainda não existiam recursos tecnológicos digitais que pudessem ser utilizados em ambientes de aprendizagem. Dessa forma, naturalmente não consideraram aspectos da constituição dos conhecimentos distribuídos em redes, pessoais ou organizacionais, conforme abordado pelo conectivismo.

Quanto aos aspectos comuns das teorias apresentadas, percebe-se que, nas abordagens cognitivista, humanista e sócio-histórica, o conhecimento é construído por meio de interações e o aluno atua de modo ativo no processo da aprendizagem.

Um aspecto comum a todas as abordagens, exceto a behaviorista, é a concepção de que o aluno, para aprender, precisa assumir uma postura ativa no processo e de que a atividade de aprendizagem deve estimular questionamentos e uma postura investigativa, impulsionando e culminando no ato do conhecer. Essa também é uma característica presente na proposta pedagógica do construcionismo de Papert (1994), que, apesar de ter propósitos diferentes do conectivismo, visa potencializar a aprendizagem dos alunos por meio de construções com o uso de computadores em ambientes escolares, isso é, da criação de ambientes colaborativos de aprendizagem.

Ressalta-se, ainda, como um aspecto comum às abordagens cognitivistas/construcionistas, que a experiência e o pensamento são fundamentais para a construção do conhecimento, sendo também considerados, de modo implícito, no desenvolvimento integral do sujeito, na perspectiva da abordagem humanista.

Apesar de a teoria de Piaget não considerar a exploração do uso de recursos tecnológicos digitais no processo de desenvolvimento cognitivo, sua abordagem cognitivista/construcionista impulsionou adaptações teóricas ou práticas, idealizadas em pesquisas posteriores, que permitiram explorá-los nos processos de aprendizagem. Nessa perspectiva, destaca-se a abordagem pedagógica do construcionismo de Papert (1994), que visou inserir o computador como um meio de aprendizagem para potencializar a construção do conhecimento escolar, a qual consistiu numa proposta pedagógica inovadora para a época, já que atendia às necessidades da educação escolar, emergentes no final do século XX.

Também se percebe uma aproximação dessa abordagem com a concepção sóciohistórica proposta por Vygotsky, uma vez que concebe que o conhecimento se constrói pela interação do sujeito com o meio em que vive por meio de atividades mediadas por instrumentos simbólicos. O computador seria um dos artefatos mediadores utilizados pelo professor em atividades propostas para o ensino. Sua teoria, anterior à criação dos recursos tecnológicos digitais, impulsionou e tem ainda fomentado diversas pesquisas na área da educação, que resultam em propostas pedagógicas que visam à construção dos conhecimentos por meio de interações potencializadas pelo uso de ferramentas tecnológicas digitais, disponibilizadas em dispositivos de tecnologias móveis, tais como calculadoras, simuladores, sites de busca, planilhas eletrônicas, softwares gráficos, etc. 


\begin{tabular}{|c|c|c|c|c|c|c|}
\hline Teori & & Behaviorista & Cognitivista & Humanista & Sócio-histórica & Conectivismo \\
\hline 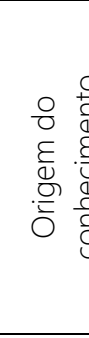 & & $\begin{array}{l}\text { Adquirido pela } \\
\text { experiência. }\end{array}$ & $\begin{array}{c}\text { Construído } \\
\text { pelo } \\
\text { pensamento e } \\
\text { pela } \\
\text { experiência em } \\
\text { interações com } \\
\text { o meio. }\end{array}$ & $\begin{array}{c}\text { Construído } \\
\text { considerando } \\
\text { aspectos integrais } \\
\text { da pessoa, nas } \\
\text { perspectivas } \\
\text { afetiva, social, } \\
\text { psicomotora e da } \\
\text { personalidade } \\
\text { humana. } \\
\end{array}$ & $\begin{array}{l}\text { Construído pelo } \\
\text { pensamento e } \\
\text { pela experiência } \\
\text { em interações } \\
\text { sociais e } \\
\text { influências } \\
\text { históricas e } \\
\text { culturais. }\end{array}$ & $\begin{array}{l}\text { Distribuído em redes e é } \\
\text { constituído por reconhecimento e } \\
\text { estabelecimento de novas } \\
\text { conexões por reconhecimento } \\
\text { crítico de novas relações, visando } \\
\text { a adaptação às mudanças de } \\
\text { padrão, percebidos em } \\
\text { problemas reais. }\end{array}$ \\
\hline \multicolumn{2}{|l|}{$\begin{array}{l}\frac{E}{0} \\
\bar{D} \\
\frac{N}{N} \\
\frac{N}{0} \\
\frac{E}{d} \\
\frac{0}{2}\end{array}$} & $\begin{array}{c}\text { Individual e } \\
\text { centrada no } \\
\text { aluno. } \\
\text { Controlada } \\
\text { pelo professor. } \\
\text { Decorrente de } \\
\text { mudança } \\
\text { observável no } \\
\text { comportament } \\
\text { o do sujeito. }\end{array}$ & $\begin{array}{l}\text { Individual e } \\
\text { centrada no } \\
\text { aluno. } \\
\text { Orientada pelo } \\
\text { professor. } \\
\text { Decorrente da } \\
\text { sua interação } \\
\text { com o meio. } \\
\text { Desenvolvimen } \\
\text { to humano } \\
\text { ocorre por } \\
\text { processos de } \\
\text { maturação de } \\
\text { estruturas } \\
\text { cognitivas. }\end{array}$ & $\begin{array}{l}\text { Individual e } \\
\text { centrada no } \\
\text { aluno. } \\
\text { Orientada e } \\
\text { mediada pelo } \\
\text { professor. } \\
\text { Decorrente de } \\
\text { experiências } \\
\text { interpessoais e } \\
\text { pessoais, } \\
\text { considerando } \\
\text { aspectos integrais } \\
\text { do sujeito. }\end{array}$ & $\begin{array}{c}\text { Individual } \\
\text { centrada no } \\
\text { aluno. Orientada } \\
\text { e mediada pelo } \\
\text { professor. } \\
\text { Decorrente de } \\
\text { relações } \\
\text { interativas, } \\
\text { estabelecidas } \\
\text { com o meio } \\
\text { social, } \\
\text { considerando as } \\
\text { influências de } \\
\text { fatores internos e } \\
\text { externos no } \\
\text { desenvolvimento } \\
\text { das estruturas } \\
\text { cognitivas. }\end{array}$ & $\begin{array}{l}\text { Individual e organizacional } \\
\text { (institucional ou corporativo) - } \\
\text { não centrada no aluno. Aprender } \\
\text { é definido como conhecimento } \\
\text { acionável, que pode ocorrer fora } \\
\text { do indivíduo e dentro de uma } \\
\text { rede organizada - sujeito e } \\
\text { organização aprendem. Não } \\
\text { controlada pelo aluno e é fluida: } \\
\text { ocorre informalmente, pela } \\
\text { experimentação, pelo diálogo, } \\
\text { pelo pensamento e por reflexão. } \\
\text { Processo contínuo, não linear: } \\
\text { exige operaçães cognitivas para } \\
\text { tratar com armazenamento e } \\
\text { recuperação de informaçães. }\end{array}$ \\
\hline \multicolumn{2}{|l|}{ 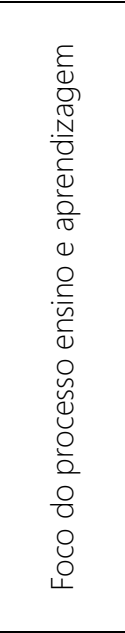 } & $\begin{array}{c}\text { Estímulos e } \\
\text { aferição de } \\
\text { respostas } \\
\text { observáveis. }\end{array}$ & $\begin{array}{l}\text { Construção de } \\
\text { conhecimentos: } \\
\text { apropriação de } \\
\text { conceitos por } \\
\text { interações com } \\
\text { o meio, } \\
\text { possibilitando o } \\
\text { estabeleciment } \\
\text { o de novas } \\
\text { relações com } \\
\text { estruturas } \\
\text { cognitivas } \\
\text { existentes. }\end{array}$ & $\begin{array}{l}\text { Valorização de } \\
\text { relações } \\
\text { interpessoais e } \\
\text { relações com o } \\
\text { desenvolvimento } \\
\text { do próprio sujeito } \\
\text { integrado na } \\
\text { construção e } \\
\text { organização da } \\
\text { realidade em que } \\
\text { vive. }\end{array}$ & $\begin{array}{c}\text { Construção de } \\
\text { conhecimentos } \\
\text { pelo } \\
\text { desenvolvimento } \\
\text { das estruturas } \\
\text { mentais } \\
\text { humanas, } \\
\text { considerando a } \\
\text { influência de } \\
\text { aspectos } \\
\text { culturais, } \\
\text { históricos e } \\
\text { sociais em } \\
\text { relações } \\
\text { interativas do } \\
\text { sujeito com o } \\
\text { meio. }\end{array}$ & $\begin{array}{c}\text { Constituição de conhecimentos } \\
\text { por meio de novas conexões em } \\
\text { redes pessoais, que formam e } \\
\text { impulsionam o aprimoramento } \\
\text { dos conhecimentos } \\
\text { organizacionais, que por sua vez } \\
\text { retroalimentam e proporcionam } \\
\text { aos sujeitos novos aprendizados } \\
\text { visa auto-organização de redes, } \\
\text { para atualização e emprego do } \\
\text { conhecimento disponível, sem a } \\
\text { necessidade do completo } \\
\text { entendimento pessoal. }\end{array}$ \\
\hline \multirow[t]{2}{*}{ 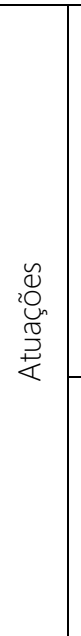 } & & $\begin{array}{c}\text { Responsável } \\
\text { pelo ensino - } \\
\text { pela } \\
\text { transmissão } \\
\text { do } \\
\text { conhecimento. }\end{array}$ & $\begin{array}{c}\text { Orientador das } \\
\text { atividades de } \\
\text { ensino, visando } \\
\text { ao } \\
\text { desenvolviment } \\
\text { o dos } \\
\text { processos } \\
\text { mentais dos } \\
\text { alunos. }\end{array}$ & $\begin{array}{l}\text { Orientador/facilita } \\
\text { dor/mediador em } \\
\text { relações } \\
\text { interpessoais, } \\
\text { visando ao } \\
\text { crescimento } \\
\text { pessoal e à } \\
\text { realização plena } \\
\text { do potencial } \\
\text { humano. } \\
\end{array}$ & $\begin{array}{c}\text { Mediador/facilita } \\
\text { dor da } \\
\text { aprendizagem, } \\
\text { planeja e } \\
\text { (re)organiza } \\
\text { experiências, } \\
\text { visando à } \\
\text { apropriação de } \\
\text { novos } \\
\text { conhecimentos. }\end{array}$ & $\begin{array}{l}\text { Mediador/facilitador da } \\
\text { aprendizagem, adota uma } \\
\text { pedagogia participativa, } \\
\text { possibilitando novas ecologias de } \\
\text { aprendizagens, valorizando a } \\
\text { diversidade, o diálogo e a } \\
\text { reflexão crítica na constituição de } \\
\text { comunidades e redes de } \\
\text { conhecimento. }\end{array}$ \\
\hline & $\frac{O}{\frac{O}{4}}$ & $\begin{array}{c}\text { Passivo, } \\
\text { recebe o } \\
\text { conhecimento } \\
\text { transmitido. }\end{array}$ & $\begin{array}{c}\text { Ativo, } \\
\text { observador das } \\
\text { suas interações } \\
\text { e solucionador } \\
\text { de problemas. }\end{array}$ & $\begin{array}{l}\text { Ativo, deve } \\
\text { perceber suas } \\
\text { necessidades e } \\
\text { autodirigir sua } \\
\text { educação. }\end{array}$ & $\begin{array}{l}\text { Ativo, aprende } \\
\text { por meio de suas } \\
\text { experiências } \\
\text { interativas com o } \\
\text { meio social. }\end{array}$ & $\begin{array}{l}\text { Ativo, aprende estabelecendo } \\
\text { novas conexões em sua rede } \\
\text { pessoal ou organizacional da qua } \\
\text { participa, reconhecendo de modo } \\
\text { crítico, onde se localiza o } \\
\text { conhecimento necessário para } \\
\text { resolver um novo problema. }\end{array}$ \\
\hline
\end{tabular}

Quadro 1 - Resumo das características das teorias de aprendizagem apresentadas. Fonte:

Elaborado pelos autores. 
Além disso, salienta-se que a teoria da aprendizagem significativa de Ausubel (1963, 1968) também foi inspirada na teoria construtivista de Piaget e foi inicialmente proposta sem intenção de exploração dos recursos das tecnologias digitais. No entanto, essa teoria também fundamentou diversas pesquisas posteriores, gerando propostas pedagógicas inovadoras para ensino e aprendizagem com uso de diversos recursos das TIC.

$\mathrm{Na}$ época em que Ausubel propôs a teoria da aprendizagem significativa, mesmo sem relacionar sua perspectiva à ideia de conexões em redes ou à ideia de hipertextos, indicou que são as relações entre conhecimentos prévios e informações potencialmente significativas que impulsionam a assimilação e a significação das novas informações recebidas pelo sujeito que possibilitam constituir e aprimorar sua rede pessoal de conhecimento.

No sentido de estabelecimento de novas conexões para aperfeiçoamento de uma rede semântica própria, para cada indivíduo, entende-se que a teoria da aprendizagem significativa de Ausubel aproxima-se da teoria do conectivismo de Siemens, diferenciandose dela pelo fato de não considerar que o conhecimento poderia ser construído ou estar distribuído em uma rede organizacional, externa ao indivíduo. Outra proximidade é o fato de Ausubel também defender que a estrutura cognitiva se constitui ou se auto-organiza por meio de aprendizagens não lineares, ocorridas ao longo da vida, que necessita do desenvolvimento de operações cognitivas para tratar do armazenamento e recuperação de informações, o que é um pressuposto da teoria conectivista.

Próxima da teoria da aprendizagem significativa, Ausubel, Novak e Hanesian (1978) propuseram a teoria da aprendizagem colaborativa, que consiste no desenvolvimento de atividades colaborativas em que professores e alunos constroem juntos modelos de conhecimento por meio de processos investigativos. Nessa abordagem teórica, os recursos tecnológicos digitais podem ser explorados auxiliando na expressão, na compreensão, na investigação e no compartilhamento dos modelos construídos em ambientes virtuais colaborativos de aprendizagem, tais como comunidades virtuais, moodle, blogs ou Wikis, ou pela exploração de recursos tecnológicos interativos, como simuladores educacionais ou softwares educativos desenvolvidos para propiciar desenvolvimento de aprendizagem mediada, que possibilitam o uso de ferramentas já existentes ou a criação de algoritmos ou simulações virtuais para auxiliar na elaboração e compreensão de modelos construídos colaborativamente. O Quadro 1 sistematiza as características principais das teorias de aprendizagens clássicas e da teoria do conectivismo e esclarece suas proximidades e/ou distanciamentos.

\section{Considerações finais}

A teoria do conectivismo, elaborada por George Siemens, sustenta uma abordagem diferenciada das demais teorias, pois se direciona à compreensão de como se constituem os conhecimentos pessoais e organizacionais, distribuídos e estruturados em redes. Para isso, o uso de recursos tecnológicos foi considerado como algo natural e indispensável.

Conclui-se que, apesar de as teorias clássicas não considerarem a inserção do uso de recursos tecnológicos digitais em contextos educacionais em seus pressupostos, as abordagens cognitivistas e as sócio-históricas impulsionaram o desenvolvimento tanto de novas teorias de aprendizagem quanto de propostas inovadoras para o ensino e a 
aprendizagem que contemplaram necessidades emergentes da inserção dos recursos das TIC em ambientes escolares, evidenciadas pela sociedade contemporânea da era digital.

Nota-se que os pressupostos teóricos presentes na teoria da aprendizagem significativa, na teoria da aprendizagem colaborativa e na teoria do conectivismo aproximam-se por conceberem que a aprendizagem ocorre por meio da constituição de redes semânticas de saberes, nas quais há a necessidade de conexões entre novos e velhos conhecimentos.

Além disso, nota-se que, desde o início do século XXI, o crescimento e a evolução dos processos de tecnologias de informação e de comunicação têm influenciado significativamente as formas de comunicação, os modos de viver e de pensar e os valores éticos e humanos. Além disso, têm influenciado, de modo especial, a forma como o conhecimento humano está sendo construído e armazenado, especialmente o conhecimento científico, que está cada vez mais disseminado. Atualmente, os avanços científicos são tantos que o conhecimento já não é mais criado apenas pelo cérebro, mas pode, também, ser gerado por meio dos computadores, utilizando-se a inteligência artificial e os sistemas inteligentes.

Em meio à transformação tecnológica, que naturalmente tem implicado transformações culturais e sociais, surge a necessidade de superar velhas estruturas propostas para o ensino e para a aprendizagem em ambientes escolarizados, de modo a se repensar as estruturas escolares como algo inevitável.

Nesse universo, se faz necessário refletir sobre as próprias práticas e concepções sobre processos vivenciados de ensino e aprendizagem, de modo que, ao adotar uma postura epistemológica reflexiva, seja possível (re)pensá-las, tendo em vista uma mudança que impulsione a proposição e a consecução de novas teorias e práticas pedagógicas inovadoras. Assim, será possível favorecer mudanças significativas nos processos de ensino e aprendizagem, proporcionando aos estudantes ambientes de aprendizagens adequados às necessidades da sociedade contemporânea, explorando ao máximo o uso dos recursos oferecidos pelas novas tecnologias, de modo a superar as atuais dificuldades que professores têm enfrentado nos contextos de ensino formais, e favorecendo o almejado enriquecimento das atuais práticas pedagógicas.

Nóvoa (2009, p. 205) afirma que "A educação vive um tempo de grandes incertezas e de muitas perplexidades. Sentimos a necessidade de mudar, mas nem sempre conseguimos definir o curso. Existe um excesso de discursos, redundantes e repetitivos, que se traduz na pobreza das práticas".

Assim, atualmente, o uso das TIC em ambientes de ensino torna-se indispensável, pois elas possuem recursos digitais que podem favorecer a aprendizagem, uma vez que se constituem como dispositivos tecnológicos de uso diário, com os quais ele tem muita familiaridade, habilidade e competência. Além disso, seus inúmeros recursos midiáticos possibilitam: perceber e compreender melhor fenômenos humanos, científicos ou da natureza (a exemplo do uso de simuladores diversos ou de geotecnologias); o acesso rápido a informações gerais, de interesse pessoal ou social; a visualização e validação de construtos mentais; o estimulo à criatividade, permitindo a abordagem de resolução de problemas por diferentes estratégias. Também, possibilitam a auto-organização do aprendizado, na construção do conhecimento pessoal ou organizacional, ocorridos em ambientes formais ou não e em tempos diferenciados, adequados às necessidades individuais de cada sujeito. 
Ao finalizar este estudo, conclui-se que a concepção construtivista e a abordagem por meio das teorias cognitivistas e sócio-históricas mantêm proximidades e distanciamentos em relação à teoria do conectivismo. No entanto, como visam à construção do conhecimento por meio do estabelecimento de redes semânticas de significados, em que os aprendentes atuam de modo ativo em processos de aprendizagem colaborativos, tais perspectivas indicam a necessidade de exploração do uso de recursos tecnológicos digitais em processos de ensino e aprendizagem. Acredita-se que o recurso a elas, adequado aos propósitos desses processos, pode potencializar a construção do conhecimento, seja ele interno, pessoal ou social, construído em comunidades aprendentes, ou externo, organizacional, distribuído e estruturado em redes.

\section{Referências}

ALVES, Laura Maria Silva Araújo Alves. Disciplina Psicologia da Aprendizagem (volume 14) - Textos didáticos do Curso de Licenciatura em Letras Habilitação em Modalidade a Distância. Belém: editAedi, UFPA, 2014.

AUSUBEL, David Paul. The Psychology of meaningful verbal learning. New York (NY): Grune and Stratton, 1963.

AUSUBEL, David Paul. Educational psychology: a cognitive view. New York (NY): Holt, Rinehart and Winston, 1968.

AUSUBEL, David Paul; NOVAK, Joseph. D., HANESIAN, Helen. Educational psychology: a cognitive view. $2 a$ ed. New York (NY): Holt, Rinehart and Winston, 1978.

DOWNES, Stephen. An introduction to connective knowledge. 2005. Disponível em: https://www.downes.ca/cgi-bin/page.cgi?post=33034. Acesso: 20 de nov. 2019.

DOWNES, Stephen. Learning Networks and Connective Knowledge. In: YANG, H. H; YUEN. S. C. (Org.). Collective Intelligence and E-Learning 2.0: Implications of Web-Based Communities and Networking, 2009, p. 1-26.

DOWNES, Stephen. What connectivism is. Half an Hour. 2007. Disponível em: http://halfanhour.blogspot.com/20 07/02/what-connectivism-is.html. Acesso: 20 de nov. 2019.

FARIA, Rejane Waiandt Schuwartz de Carvalho; ROMANELLO, Laís Aparecida; DOMINGUES, Nilton Silveira. Fases das tecnologias digitais na exploração matemática em sala de aula: das calculadoras gráficas aos celulares inteligentes. Amazônia - Revista de Educação em Ciências e Matemáticas, v.14, n. 30, p. 105-122, 2018.

HESSEN, Johannes. Teoria do conhecimento. São Paulo (SP): Martins Fontes, 2000.

JONASSEN, David. O uso das novas tecnologias na educação a distância e a aprendizagem construtivista. Em Aberto. Brasília, ano 16, n. 70, p. 70-88, abr./jun, 1996.

KERR, Bill. A Challenge to Connectivism. Transcrição da comunicação apresentada na Online Connectivism Conference, Fev., 2007, Universidade de Manitoba. Disponível em: http://tc.umanitoba.ca/wiki/index.php?title=Kerr_Presentation. Acesso em: 15 dez. 2008.

KOP, Rita; HILL, Adrian. Connectivism: Learning theory of the future or vestige of the past? The International Review of Research in Open and Distance Learning, v. 9, n. 3, 2008.

LOPES, Rosemara Perpetua. Concepções e práticas declaradas de ensino e aprendizagem com TD/C em cursos de Licenciatura em Matemática. Tese de doutorado. Faculdade de Ciências e Tecnologia da Universidade Estadual Paulista. Presidente Prudente, 2014. 
NÓVOA, Antônio. Para una formación de profesores construida dentro de la profesión. Revista de Educación, 350, p. 203-218, set/dez, 2009.

MACHADO, Claudia, FARIAS, Maria Auxiliadora de Almeida. Das teorias pré-tecnológicas às abordagens colaborativas. In: II CONGRESSO INTERNACIONAL TIC E EDUCAÇÃO, 2, 2012, Lisboa, Portugal. Anais... Lisboa: Faculdade de Arquitectura da Universidade do Porto, 2012. p. 409-418.

MOREIRA, Marco Antonio; MASINI, Elcie F. Salzano. Aprendizagem significativa - A teoria de David Ausubel. São Paulo: Editora Moraes, 1982.

MOTA, José. Da Web 2.0 ao e-Learning 2.0: aprender na rede. Dissertação de Mestrado, Versão Online, Universidade Aberta. Ago, 2009.

OLIVEIRA, Celina Couto de; COSTA, José Wilson da; MOREIRA, Márcia. Ambientes informatizados de aprendizagem: produção e avaliação de software educativo. Campinas (SP): Papirus, 2001.

PAPERT, Seymour. A máquina das crianças: repensando a escola na era da informática. Porto Alegre (RS): Artes Médicas, 1994.

RAMOS, Maurivan. Güntzel. Epistemologia e ensino de ciências: compreensões e perspectivas. In: Roque Moraes. (Org.). Construtivismo e ensino de ciências: reflexões epistemológicas e metodológicas. 3a ed. Porto Alegre (RS): EDIPUCRS, p. 13-36. 2008.

SIEMENS, George. Connectivism: a learning theory for the digital age. International Journal of Instructional Technology and Distance Learning, v. 2, n. 1, dez, 2004.

SIEMENS, George. Knowing knowledge. 2006. Disponível em: http://www.elearnspace.org/KnowingKnowledge_LowRes.pdf. Acesso em: 20 de nov. 2019.

SIEMENS, George. New structures and spaces of learning: The systemic impact of connective knowledge, connectivism, and networked learning. Comunicação apresentada no Encontro sobre Web 2.0, Universidade do Minho, Braga, 2008.

SILVA, Claci Clair Röpke; PORTO, Marcelo Duarte, MEDEIROS, Wilton de Araújo. A teoria Vygotskyana e a utilização das novas tecnologias no ensino aprendizagem: uma reflexão sobre o uso do celular. Revista online De Magistro de Filosofia, Ano X, no. 21, pp. 84-98, jan./jun., 2017.

SOUZA, Renato Rocha. Algumas considerações sobre as abordagens construtivistas para a utilização de tecnologias na educação. Lïnc em Revista, v.2, n.1, p. 40-52, mar, 2006.

SOUZA FILHO, Moacir Pereira de; SOUZA, Agda Eunice de; GIBIN, Gustavo Bizarria. Uso de recursos tecnológicos no ensino de ciências: produção de videoaulas didáticos-experimentais pelos futuros professores. Nuances: estudos sobre Educação, Presidente Prudente (SP), v. 28, n. 3, p. 133-149, Set/Dez, 2017.

URDANETA, Stephanie Chiquinquira Diaz; GONZALEZ, Juan Luis Prieto; CASTILLO, Ana Duarte. Interpretação geométrica dos signos das razões trigonométricas com Geogebra. Amazônia: Revista de Educação em Ciências e Matemática, v.13, n. 28, Jul/Dez, p.78-89, 2017.

VERHAGEN, Plon. Connectivism: A new learning theory? Surf e-learning themasite. 2006. Disponível em: http://e-learning.surf.nl/e-learning/english/3793. Acesso em: 15 de dez. de 2008. 